(c) American Dairy Science Association, 2007.

\title{
An Observational Analysis of Twin Births, Calf Sex Ratio, and Calf Mortality in Holstein Dairy Cattle
}

\author{
N. Silva del Río, ${ }^{*}$ S. Stewart,† P. Rapnicki,† Y. M. Chang, ${ }^{\star}$ and P. M. Fricke ${ }^{\star 1}$ \\ ${ }^{*}$ Department of Dairy Science, University of Wisconsin, Madison 53706 \\ †Department of Veterinary Population Medicine, University of Minnesota, St. Paul 55108
}

\begin{abstract}
A data set of Holstein calving records from January 1996 to September 2004 comprising 4,103 herds with $2,304,278$ calving events representing $1,164,233$ cows and 96,069 twin births was extracted from Minnesota Dairy Herd Improvement Association archives to assess reported twinning trends and calf mortality across time. Overall, the reported twinning rate was $4.2 \%$, and twinning increased with parity [1.2\% for nulliparous vs. $5.8 \%$ for multiparous cows; odds ratio $(\mathrm{OR})=4.9$ ], and with time (3.4\% in 1996 to $4.8 \%$ in 2004), with a parity by time interaction. Independent of parity, the greatest twinning rate was observed when conception occurred from August to October compared with other seasons $(\mathrm{OR}=1.2)$. Calf mortality was greater after twin births, with $28.2 \%$ of twin calving events reporting one or both calves as dead, compared with $7.2 \%$ for singleton births $(\mathrm{OR}=6.5)$. Calf mortality for primiparous and multiparous cows was $5.0 \%$ after a single birth and $25.5 \%$ after twin births, whereas for nulliparous heifers, mortality was $10.4 \%$ for singletons and $38.0 \%$ for twins $(\mathrm{OR}=3.4)$. Calf sex ratio (male, $\mathrm{M}$; female, F) was $53.3 \% \mathrm{M}$ and $46.7 \% \mathrm{~F}$ for singleton calves, and $30.1 \% \mathrm{MM}, 43.6 \% \mathrm{MF}$, and $26.3 \% \mathrm{FF}$ for twin calves. Although specific factors cannot be implicated, the increase in twinning across time suggests a concurrent change in one or more causative factors associated with twinning during the 9-yr study period.
\end{abstract}

Key words: Holstein, twinning, calf sex ratio, calf mortality

\section{INTRODUCTION}

Twinning is an undesirable reproductive outcome in dairy cattle production systems and reduces profitability through negative effects on calves born as twins as well as on cows calving twins (Fricke, 2001). Economic analyses have estimated farm losses for every twin

Received July 5, 2006.

Accepted September 14, 2006.

${ }^{1}$ Corresponding author: pmfricke@wisc.edu birth at about $\$ 110$ (Eddy et al., 1991; Beerepoot et al., 1992). Dams carrying twins have a greater incidence of abortion, retained placenta, and metritis. Twinning has a detrimental effect during the subsequent lactation by decreasing the milk production and fertility of dams calving twins and by increasing the likelihood of dams calving twins being culled (Nielen et al., 1989). Moreover, despite the increase in calves born after twin births, the greater perinatal mortality for calves born as twins reduces the overall number of heifers available as herd replacements (Nielen et al., 1989; Day et al., 1995). Calf mortality within the first week of life was $63.5 \%$ of all deaths occurring by 3 mo of age (Larvor, 1975) and $67.4 \%$ occurring by 8 wk of age (Sellers et al., 1968). Reported perinatal mortality, however, varies widely among countries and among herds within the same country (Simensen, 1982; Meyer et al., 2001). Several factors have been associated with perinatal mortality of Holstein calves including sire, sex of the calf, parity of the dam, dystocia, season, and twinning (Wijeratne and Stewart, 1970; Mee, 1991).

The objectives of this study were to analyze reported twinning trends across time and to benchmark reported calf sex ratio and neonatal calf mortality for singleton and twin births in Holstein dairy cattle in the Upper Midwest region of the United States.

\section{MATERIALS AND METHODS}

\section{Assembly and Structure of the Data Set}

Calving records from Minnesota DHIA archives collected from January 1996 to September 2004 comprising 2,900,708 Holstein calving events from 6,226 herds were included in the initial data set. Information for individual calving events, including herd identification, cow identification, calving date, parity of dam, multiple births, calf gender, and perinatal calf mortality, were included in the data set. The number of calves born per calving event was coded as a dichotomous variable $(0=$ singleton; 1 = twin), and triplet births were eliminated from the data set because of the small frequency of triplet births. Calf sex for singleton births was coded $\mathbf{M}$ for males and $\mathbf{F}$ for females, whereas calf sex for 
twin births was coded as MM for male pairs, FF for female pairs, and FM or MF for mixed-sex pairs. Perinatal mortality for singleton calves was coded as $\mathbf{A}$ for calves born alive and $\mathbf{D}$ for calves born dead, whereas perinatal mortality for twin calves was coded as AA when both calves were born alive, DD when both calves were born dead, and DA when only one of the twin calves survived. Herd personnel were responsible for record keeping; thus, this data set comprises status information as reported to DHIA rather than actual events. Data extracted from DHIA archives was downloaded into a database program (Microsoft Access 2002; Microsoft Corporation, Redmond, WA) for organization and manipulation of data before statistical analysis using SAS (SAS Institute, 1999).

\section{Data Screens}

The initial data set was subjected to a screening process using the Proc Freq and Proc Sort procedures of SAS (SAS Institute, 1999) as follows. Duplicate observations, accounting for 18,000 events and 172,603 observations, from herds reporting missing information in all variables under study for all observations were removed. In addition, calving events from cows with parity $>7$, which accounted for 30,390 observations, were removed from the initial data set to better represent the general population of Holstein cows. Also, 69,952 records from herds contributing fewer than 100 total complete calving events during the 9 -yr study period were removed to avoid including herds that were enrolled in DHIA for a short duration as well as seasonal bias from herds with less than $1 \mathrm{yr}$ of data included in the DHIA program. After removal of the previously mentioned observations, a total of 2,609,763 calving events from 4,103 herds remained in the data set. A total of 305,485 of these observations were removed because the records were incomplete, that is, lacking information regarding the number of calves born, perinatal calf mortality, or calf sex.

The final data set included a total of 2,304,278 calving events from 1,164,233 Holstein cows, with $46.0 \%$ of these cows included only once. Twin calvings accounted for 96,069 of the total observations. First-parity cows represented $36.0 \%$, whereas second- and third- and greater parity accounted for 26.5 and $37.5 \%$ of the records, respectively. Overall, 85\% of herds recorded fewer than 100 Holstein calving events per year (range $=12$ to 2,105$)$.

In a preliminary analysis, the overall number of incomplete calving events decreased over time, representing $14.3 \%$ of the calving records in 1996 compared with $6.3 \%$ in 2004 (Figure 1). Thus, the final data set was further explored to assess potential trends over time

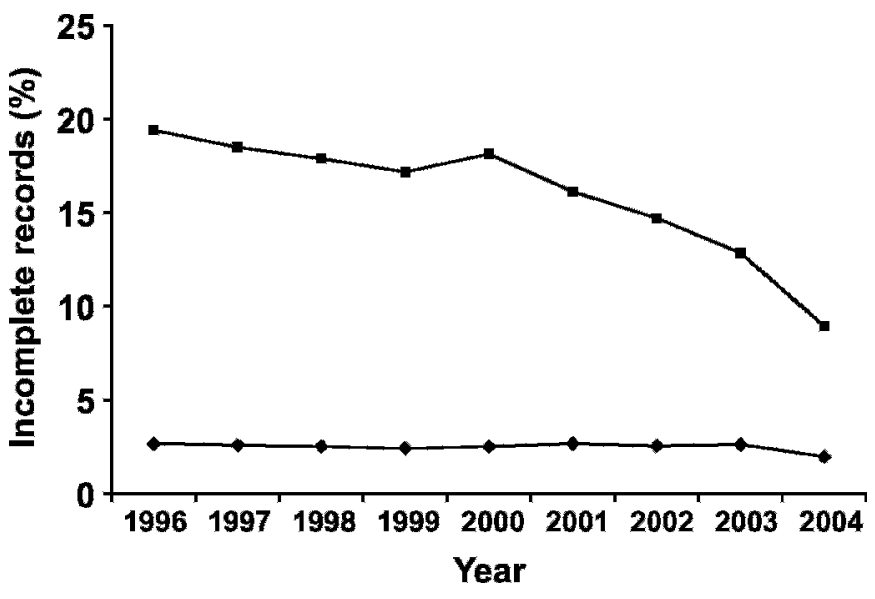

Figure 1. Frequency of incomplete observations over time for the final data set based on 2,318,601 calving records from 4,123 herds (squares) and a subset of the final data set based on 902,228 calving records from 1,754 herds (diamonds), which included only herds that reported less than $10 \%$ missing calving information during any year.

related to inaccuracy in record keeping. To accomplish this, a subset of the final data set was created after removing all calving records from herds with more than $10 \%$ incomplete records during any given year of the data collection period. This data subset included 902,380 observations from 1,754 herds. Although numerically different, results after this preliminary scrutiny did not reveal a bias for mortality, gender, or twinning (Table 1), assuring us of the veracity of the information included in the final data set. Therefore, results reported throughout are from the final data set, which included 2,304,278 calving events from 1,164,233 Holstein cows.

\section{Statistical Analyses}

A multivariable logistical regression model was constructed to analyze twinning and perinatal calf mortal-

Table 1. Comparison of the final data set and a data subset that included only the herds reporting less than $10 \%$ missing calving information during any year of the study

\begin{tabular}{lcc}
\hline Item & Final data set & Data subset \\
\hline Calving events, $\mathrm{n}$ & $2,318,601$ & 902,228 \\
Cows, n & $1,088,962$ & 413,458 \\
Herds, n & 4,123 & 1,754 \\
Twining events, n & 96,222 & 36,023 \\
Twins, \% & 4.15 & 3.99 \\
Overall calf sex ratio, \% male & 53.3 & 53.3 \\
Sex ratio of twin calves, \% male & 51.9 & 51.9 \\
Calf mortality & & \\
First parity, \% & 11.3 & 10.4 \\
First-parity twin, \% & 30.7 & 30.3 \\
>First parity, \% & 5.3 & 5.0 \\
>First-parity twin, \% & 20.1 & 19.0 \\
\hline
\end{tabular}


ity using the maximum likelihood method of the LOGISTIC procedure of SAS (SAS Institute, 1999). The model used to analyze twinning across time included the main effects of calving season (January to March, S1; April to June, S2; July to September, S3; October to December, S4), parity (nulliparous heifers, P1; primiparous cows, P2; multiparous cows, $\mathbf{P + 3}$ ) and sex of the calf ( $\mathrm{M}$ vs. F), with year included as a covariate in the model:

$$
\begin{gathered}
\text { model Logit }(\text { Twin })=\text { Parity }+ \text { Season }+ \text { Yr }+ \text { Yr } \\
\times \text { Parity }+ \text { Yr } \times \text { Yr }+ \text { Yr } \times \text { Yr } \times \text { Parity } .
\end{gathered}
$$

For the twinning incidence by season for nulliparous heifers vs. multiparous cows, 2 independent data sets were created, one with $\mathrm{P} 1$ and another with P2 and P3+. The model used for this analysis included

$$
\text { model Logit }(\text { Twin })=\text { Season }+\mathrm{Yr}+\mathrm{Yr} \times \mathrm{Yr} \text {. }
$$

Perinatal calf mortality for calves born as singletons was analyzed in a model in which the following variables were included: season (S1, S2, S3, and S4), parity (P1, P2, and P3+), sex of the calf (M vs. F), and year as a covariate:

$$
\begin{gathered}
\text { model Logit (Mortality) }=\text { Season }+ \text { Parity }+ \text { Gender } \\
+\mathrm{Yr}+\mathrm{Yr} \times \mathrm{Yr}+\mathrm{Yr} \times \mathrm{Yr} \times \mathrm{Yr}+\mathrm{Yr} \times \text { Parity } .
\end{gathered}
$$

Perinatal calf mortality for calves born as twins was analyzed in a model in which the following variables were included: season (S1, S2, S3, and S4), parity (P1, $\mathrm{P} 2$, and $\mathrm{P} 3+$ ), gender, and year as a covariate:

$$
\begin{gathered}
\text { model Logit }(\text { Mortality })=\text { Season }+ \text { Parity }+ \text { Gender } \\
+\mathrm{Yr}+\mathrm{Yr} \times \mathrm{Yr}+\mathrm{Yr} \times \mathrm{Yr} \times \mathrm{Yr} .
\end{gathered}
$$

Perinatal calf mortality for calves born as singletons and twins was analyzed in a model in which the following variables were included: season ( $\mathrm{S} 1, \mathrm{~S} 2, \mathrm{~S} 3$, and $\mathrm{S} 4)$, parity (P1, P2, and P3+), and calf number (singleton vs. twins) with year as a covariate:

$$
\begin{aligned}
& \text { model Logit (Mortality) }=\text { Season }+ \text { Calf Number } \\
& + \text { Parity + Calf Number } \times \text { Parity }+ \text { Yr }+ \text { Yr } \times \text { Yr } \\
& + \text { Yr } \times \text { Yr } \times \text { Yr } .
\end{aligned}
$$

Model selection was based on the Bayesian information criterion and the fit of all statistical models was evaluated by using the Hosmer and Lemeshow goodness-of-fit test of SAS (Hosmer and Lemeshow, 2000) by including the "lackfit" option in the model statement.

\section{RESULTS AND DISCUSSION}

\section{Reported Twinning and Twinning Trends Across Time}

Parity. The greatest difference in reported twinning rate occurred between nulliparous heifers $(1.2 \%)$ and primiparous and multiparous cows $[5.8 \% ; P<0.01$; odds ratio $(\mathbf{O R})=4.9$ ]. Interestingly, twinning not only increased from first to second parity $(\mathrm{OR}=3.8)$, but also from second to third parity $(\mathrm{OR}=1.3)$ to reach a plateau for the remaining parities (Table 2 and Figure 2). Our results agree with Cady and Van Vleck (1978), who reported twining greater for third and greater parity cows $(6.2 \%)$ than for primiparous cows (1.1\%). Nielen et al. (1989) reported the odds of twinning for primiparous cows to be 0.2 and the odds for second parity of 0.6 compared with older cows in the Netherlands; however, no differences were observed when third-parity cows were compared with older cows. Similarly, Ryan and Boland (1991) reported an increasing trend for twinning with parity for Holstein cows in Saudi Arabia, with the most dramatic increase in twinning occurring between first- and second-parity cows. The increase in twinning with parity might occur because nonlactating heifers are less able to maintain twin fetuses until calving, aborting either one or both fetuses before calving (Von Vandeplassche et al., 1979). Lactating dairy cows, however, are at greater risk for twinning because of their greater occurrence of multiple ovulations (Wiltbank et al., 2000) compared with nonlactating heifers (Rivera et al., 2004, 2005).

Parity by Time. The increased twinning rate over time was defined by a quadratic effect $(P<0.01)$, increasing from $3.4 \%$ in 1996 to $4.8 \%$ during the last 12 mo of data collection (October 2003 to September 2004). Interestingly, there was a parity by time interaction for twinning rate (Table 2; $P<0.05$ ). For primiparous and multiparous cows, the twinning rate increased from 4.0 and $5.2 \%$ during the first 12 mo of the study to 5.9 and $7.3 \%$ during the last $12 \mathrm{mo}$ of the study, whereas the twinning rate for nonlactating heifers increased from 1.1 to $1.3 \%$ during this same time period (Figure 2 ). The estimated change in reported twinning relative to the previous year averaged $4.0,4.8$, and $3.7 \%$ for nulliparous, primiparous, and multiparous cows, respectively (Table 3). Previous studies have reported an increase in twinning rate over time (Kinsel et al., 1998; Ron et al., 1990). Twinning increased from 1.4 to $2.4 \%$ from 1983 to 1993 for Holstein cows in North America (Kinsel et al., 1998). In Israeli Friesian-Holstein herds from 1964 to 1970, the twinning rate for second- and third-parity cows averaged 4.5\% (Bar-Anan and Bowman, 1974), whereas for the same population, the overall increase in twinning rate from 1980 to 1987 was 
Table 2. Estimated odds ratios and their 95\% confidence intervals (CI) for the effect of parity of dam, year (Yr), and season of calving on reported twinning rates of Holstein cows from 1996 to 2004

\begin{tabular}{|c|c|c|c|c|c|}
\hline Variable & Class & Estimates & $P$ & $\begin{array}{l}\text { Odds } \\
\text { ratio }\end{array}$ & $95 \% \mathrm{CI}$ \\
\hline \multirow[t]{3}{*}{ Parity of dam } & Nulliparous & - & - & 1 & - \\
\hline & Primiparous & 0.3538 & $<0.001$ & 3.77 & $3.69-3.86$ \\
\hline & Multiparous & 0.6198 & $<0.001$ & 4.92 & $4.80-5.05$ \\
\hline $\mathrm{Yr}$ & & 0.0752 & $<0.001$ & 1.078 & $1.069-1.086$ \\
\hline $\mathrm{Yr} \times \mathrm{Yr}$ & & -0.00310 & $<0.001$ & 0.996 & $0.996-0.997$ \\
\hline \multirow[t]{3}{*}{ Yr $\times$ Parity } & Nulliparous & - & - & 1 & - \\
\hline & Primiparous & 0.0322 & 0.012 & 1.10 & $1.02-1.20$ \\
\hline & Multiparous & -0.019 & 0.036 & 1.18 & $1.03-1.34$ \\
\hline \multirow[t]{3}{*}{$\mathrm{Yr} \times \mathrm{Yr} \times$ Parity } & Nulliparous & - & - & 1 & - \\
\hline & Primiparous & -0.003 & 0.002 & 0.91 & $0.79-0.99$ \\
\hline & Multiparous & 0.002 & 0.063 & 0.95 & $0.88-1.00$ \\
\hline \multirow[t]{4}{*}{ Season of calving } & Jan to Mar & -0.117 & $<0.001$ & 0.91 & $0.90-0.93$ \\
\hline & Apr to Jun & 0.113 & $<0.001$ & 1.15 & $1.13-1.17$ \\
\hline & Jul to Sep & 0.030 & $<0.001$ & 1.06 & $1.06-1.08$ \\
\hline & Oct to Dec & - & - & 1 & - \\
\hline
\end{tabular}

$5.4 \%$ (Ron et al., 1990). Additionally, the twinning rate increased from 0.3 to $0.9 \%$ for nonlactating heifers and from 1.4 to $2.6 \%$ for second-parity cows from 1978 to 1995 in dairy herds in Norway (Karlsen et al., 2000).

In the present study, the increase in reported twinning rate across time suggests a concurrent change in one or more of the causative factors associated with twinning; however, no specific factors can be implicated based on this observational data set. Dizygous twinning accounts for $95 \%$ of twin births in Holstein cattle (Silva del Río et al., 2006) and is a complex trait with multiple

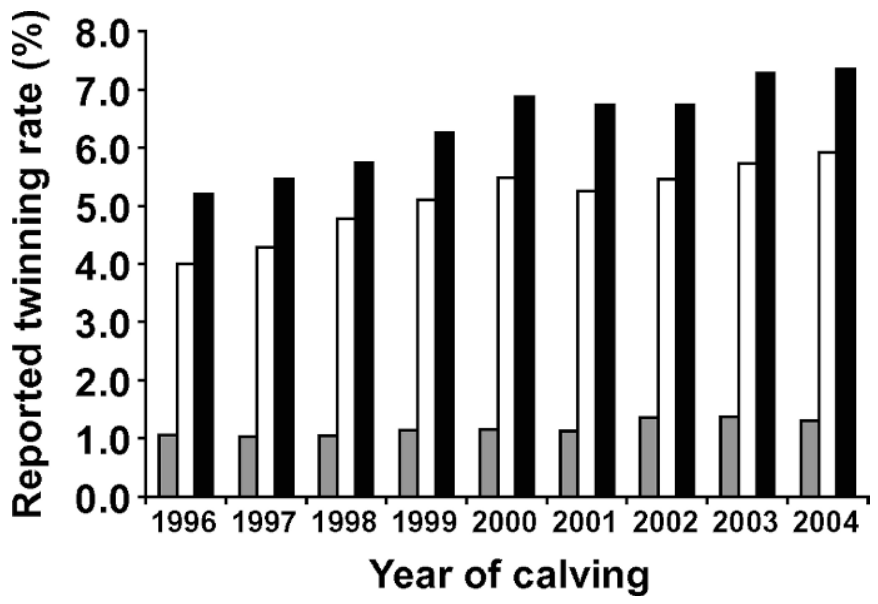

Figure 2. Twinning rates of Holstein dairy cattle from 1996 to 2004 by parity. Gray bars = nulliparous heifers; open bars = primiparous cows; black bars $=$ multiparous cows. The overall twinning rate increased $(P<0.01)$ from $3.4 \%$ in 1996 to $4.8 \%$ in 2004 . Twinning was greater $[P<0.01$; odds ratio $(\mathrm{OR})=1.3]$ for multiparous than for primiparous cows, and was greater $(P<0.01 ; \mathrm{OR}=3.8)$ for primiparous cows than for nulliparous heifers. There was a parity by time interaction in which the increase in twinning over time was greater $(P<0.05)$ for primiparous and multiparous cows than for nulliparous heifers. causative factors, including multiple ovulation rate, milk production, parity, season, and genetics (Fricke, 2001). Johanson et al. (2001) reported a greater twinning rate among daughters of bulls born between 1991 and $1998(5.9 \%)$ compared with daughters of bulls born before $1980(4.5 \%)$ when investigating the sire-predicted transmitting abilities for twinning rate, suggesting a possible role for genetic selection in the increase in twinning over time. Indeed, the estimated breeding value for the frequency of twinning in Norwegian dairy herds increased over time from 1978 to 1995 and averaged 0.003 for nullliparous and 0.016 for primiparous cows (Karlsen et al., 2000).

In the present study, a greater increase in reported twinning rate over time was observed for lactating cows compared with nonlactating heifers when twinning rate was expressed as absolute percentage units (2.0 vs. $0.2 \%$ ). Although a causal relationship cannot be established, this greater increase in twinning with time may implicate the concurrent increase in milk production as a causative factor associated with twinning. Indeed, Kinsel et al. (1998) reported that peak milk production was a major risk factor for increased twinning rates in lactating dairy cows.

Herd. The reported twinning rate was $4.2 \%$, falling within the range of 2.2 to $6.9 \%$ reported in previous studies (Day et al., 1995; Kinsel et al., 1998). In the present study, the incidence of twinning across farms ranged from 0.3 to $12.0 \%$ (Figure 3 ). Similarly, previous reports with twinning rates of 3.2 and $2.4 \%$, respectively, reported twinning rates ranging from 0 to $9.6 \%$ among farms (Nielen et al., 1989; Kinsel et al., 1998).

Season. Independent of parity, the greatest occurrence of twinning was observed in calving season $\mathrm{S} 2$, when conception occurred from August to October $(\mathrm{OR}=$ 1.2; $P<0.01$ ), compared with the remaining 9 mo of 
Table 3. Estimated twinning rate of Holstein cows by year and parity, and the change in twinning relative to the previous year

\begin{tabular}{|c|c|c|c|c|c|c|}
\hline \multirow{2}{*}{$\begin{array}{l}\text { Year } \\
\text { of birth }\end{array}$} & \multicolumn{3}{|c|}{ Estimated twinning rate, $\%$} & \multicolumn{3}{|c|}{$\begin{array}{c}\text { Change in estimated twinning rate relative } \\
\text { to the previous year, } \%\end{array}$} \\
\hline & Nulliparous & Primiparous & Multiparous & Nulliparous & Primiparous & Multiparous \\
\hline 1996 & 1.02 & 4.02 & 5.12 & - & - & - \\
\hline 1997 & 1.05 & 4.37 & 5.49 & 2.65 & 9.08 & 7.74 \\
\hline 1998 & 1.08 & 4.70 & 5.83 & 3.03 & 7.84 & 6.56 \\
\hline 1999 & 1.11 & 4.99 & 6.13 & 3.41 & 6.61 & 5.39 \\
\hline 2000 & 1.16 & 5.25 & 6.37 & 3.79 & 5.40 & 4.23 \\
\hline 2001 & 1.20 & 5.46 & 6.55 & 4.17 & 4.21 & 3.08 \\
\hline 2002 & 1.26 & 5.61 & 6.67 & 4.55 & 3.02 & 1.95 \\
\hline 2003 & 1.32 & 5.71 & 6.73 & 4.93 & 1.85 & 0.83 \\
\hline 2004 & 1.39 & 5.75 & 6.71 & 5.32 & 0.70 & -0.27 \\
\hline
\end{tabular}

the year (Figure 4 and Table 2). For second and greater parities, but not for nulliparous cows, fewer twins were conceived from April to June (calving $\mathrm{S} 1=5.4 \%$ ) compared with the remaining months of the year $(6.5 \% ; P$ $<0.01$; OR $=0.84)$. Similar outcomes were reported for cows in regions of the world with climates comparable to the Upper Midwest of the United States, including the Netherlands (Nielen et al., 1989) and the Midwest region of the United States (Cady and Van Vleck, 1978; Silva del Río et al., 2006). Johansson et al. (1974) found 2 yearly peaks of twinning corresponding to cows conceiving in the early spring and from September to October in Northern Europe; however, in primiparous cows, a single yearly peak was observed for cows conceiving in the autumn.

The seasonal variation in reported twinning rate during late summer to early autumn could be explained by variation in the ambient temperature. Indeed, Sart-

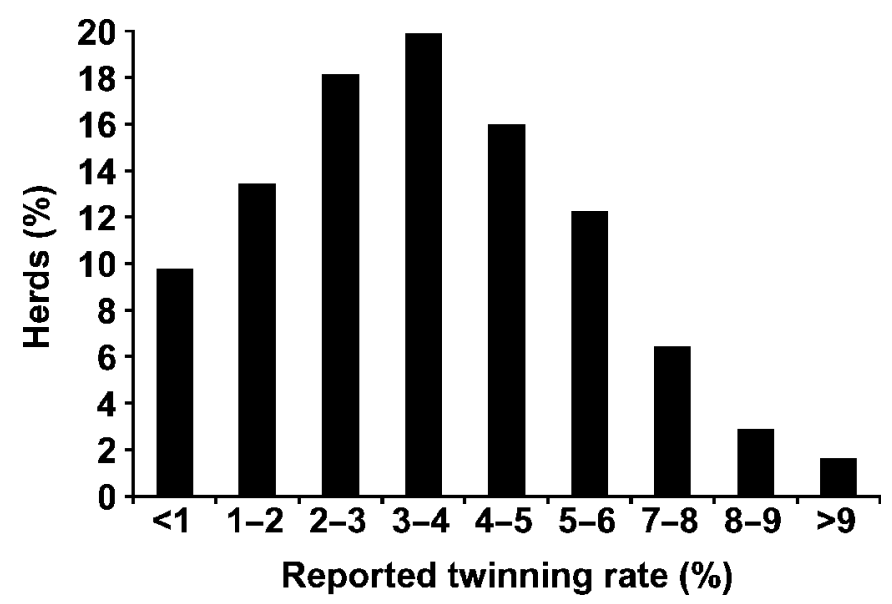

Figure 3. Distribution of reported twinning rates of Holstein dairy cattle from 1996 to 2004 by herd. The analysis included 2,304,278 calving records from 4,103 herds in the Upper Midwest region of the United States, representing 1,164,233 Holstein cows and 96,069 twin births. ori et al. (2002) reported that the double ovulation rate was greater during warmer months under US Midwest weather conditions. During late summer until early autumn, a reduction in early embryonic loss attributable to decreased heat stress during a time of increased double ovulations and conception of twins may cause the seasonal variation in twinning. Photoperiod, nutritional flushing, or both have been speculated to affect

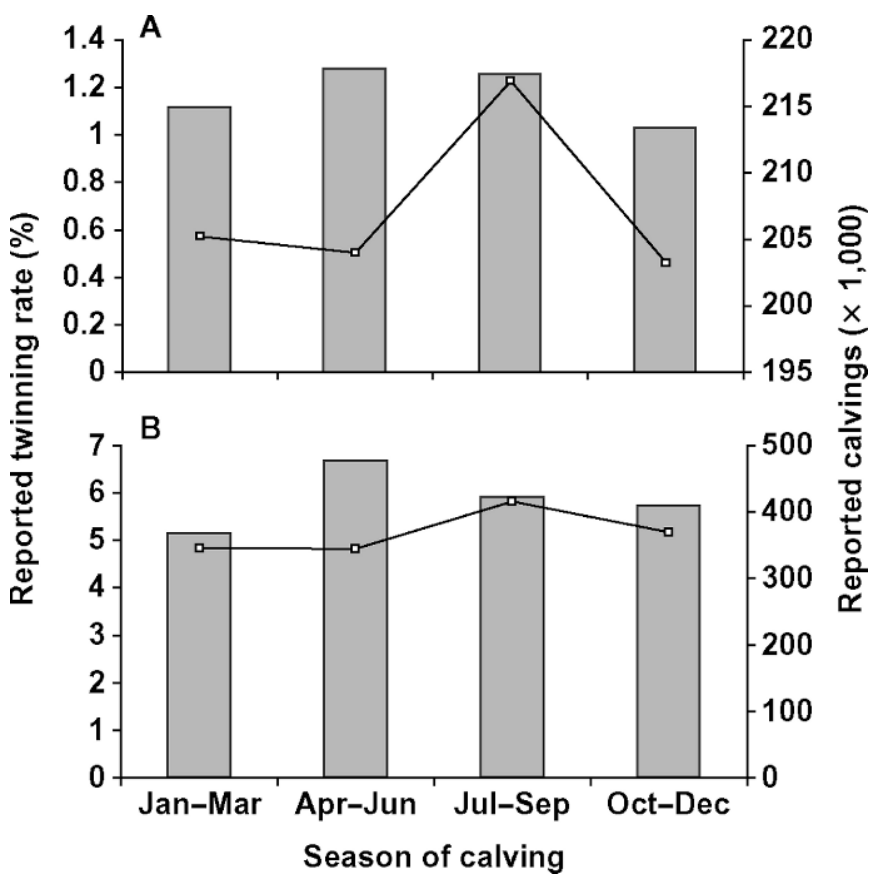

Figure 4. Reported twinning rates of Holstein dairy cattle from 1996 to 2004 by season of calving. The solid lines represent the number of reported calvings for each season (gray bars). Panel A = distribution of twinning by season of calving for nulliparous heifers; panel $\mathrm{B}=$ distribution of twinning by season of calving for primiparous and multiparous cows. Twinning was greater $[P<0.01$; odds ratio $(\mathrm{OR})=1.2]$ when calving occurred from April to June. Primiparous and multiparous cows, but not nulliparous heifers, calved fewer $(P$ $<0.01$; OR $=0.84$ ) twins from January to March. 


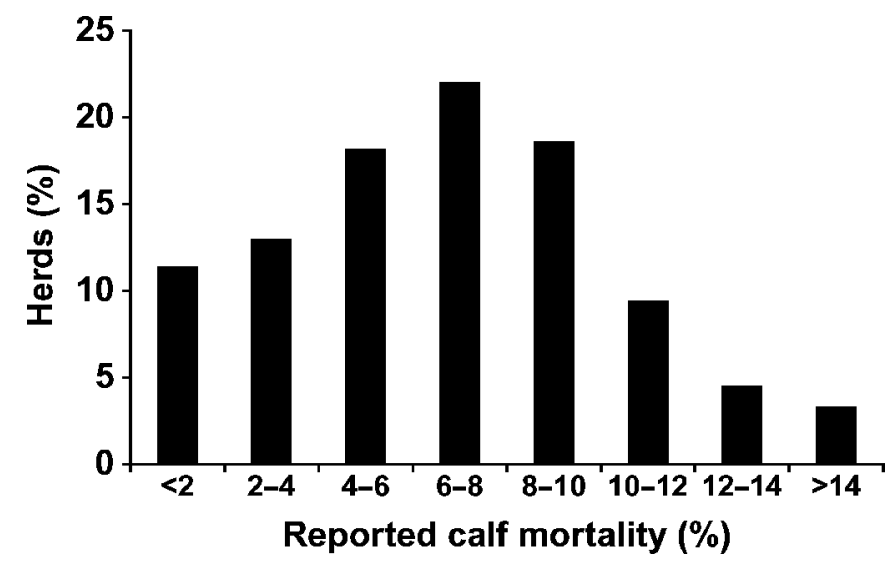

Figure 5. Distribution of reported calf mortality of Holstein dairy cattle from 1996 to 2004 by herd in the Upper Midwest region of the United States, representing 1,164,233 Holstein cows.

the seasonal variation in twinning (Johansson et al., 1974; Nielen et al., 1989).

Recurrence of Twinning. Among cows that had twinned once, the chance of delivering twins again was $7.0 \%(5,852 / 83,065)$, whereas among cows that had twinned 2 or more times, the chance of delivering twins again was $7.2 \%(421 / 5,852)$. Similarly, Nielen et al. (1989) reported that $9.3 \%$ of cows that had twinned once and $12.5 \%$ of those having twinned twice delivered twins again. These results may underestimate the true recurrence of twinning in these data sets because cows calving twins are of greater parity and at a greater risk of culling during the subsequent lactation (Nielen et al., 1989).

\section{Reported Perinatal Mortality in Holstein Calves}

Herd. The overall perinatal mortality was $8.0 \%$, similar to the perinatal mortality reported for dairy cattle in previous studies (Simensen, 1982). In the present study, the perinatal mortality among herds ranged widely, from 0.2 to $26.4 \%$ (Figure 5). Interestingly, there was an increase in singleton calf mortality as herd size increased (Figure 6; $P<0.01$; OR = 1.05), with herds with $<100$ calvings/yr reporting $6.7 \%$ perinatal mortality vs. $7.9 \%$ for herds with $>1,000$ calvings/yr. Caution must be applied when interpreting the effect of herd size on perinatal calf mortality. One explanation for these results may be that individual cows are less intensively managed during calving in larger herds; however, larger herds represented in this data set may have more accurately reported calf mortality than smaller herds, or perhaps the effect is due to herd expansion rather than the effect of herd size itself. Calf mortality did not differ when calving events occurred on a weekday compared with on weekends.

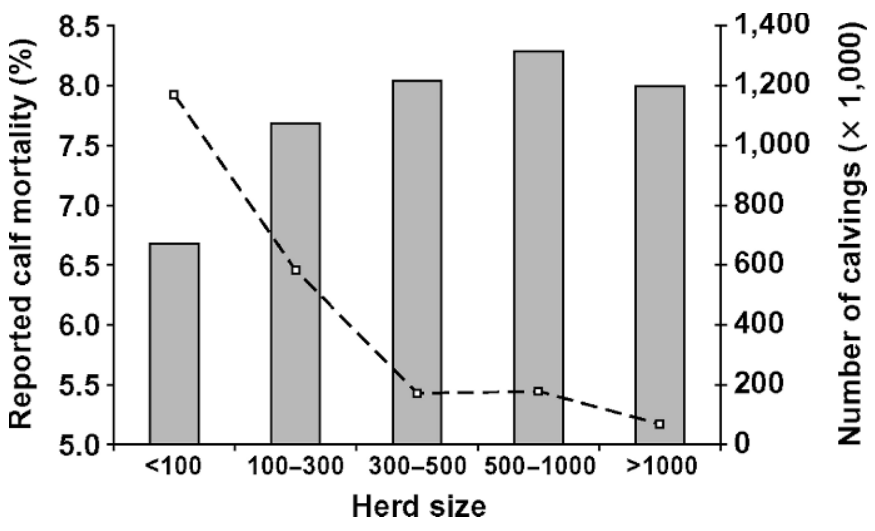

Figure 6. Calf mortality of Holstein dairy cattle from 1996 to 2004 by herd size. The dashed line represents the number of calving observations reported for each herd size category (gray bars). Singleton calf mortality increased $(P<0.01)$ with herd size category.

Parity. Greater perinatal mortality existed for calves born from nulliparous heifers than from lactating cows $(P<0.01)$ for calves born both as singletons $(11.3 \mathrm{vs.}$ $5.3 \%$ ) and as twins (30.7 vs. $20.1 \%$; Tables 4 to 8 ). In a review of the literature, Philipsson (1976) reported the occurrence of stillbirths in dairy breeds as ranging from 2.5 to $16.1 \%$ for nulliparous heifers and from 1.2 to $3.9 \%$ for lactating cows.

Parity by Time. Mortality over time was defined by a quadratic and cubic effect $(P<0.01)$, with a significant parity by time interaction for singleton births (Figures 7 and 8 , Table $5 ; P<0.01$ ), but not for twin births (Table 7). For calves born as singletons, the estimated change in mortality rate relative to the previous year averaged $3.1,1.1$, and $1.7 \%$ for nulliparous, primiparous, and multiparous cows, respectively, whereas for calves born as twins, the estimated change in mortality rate was $0.53 \%$ for nulliparous and $0.62 \%$ for primiparous and multiparous cows (Tables 6 and 8).

Twin vs. Singleton Births. Calf mortality was greater after twin births, with $28.2 \%$ of the twin calving events reporting calves as DD or DA compared with $7.2 \%$ for singleton births $(P<0.01$; OR $=6.5$; Table 4$)$. The total number of live calves produced per dam was 1.7 for twin births $(51.9 \% \mathrm{M})$ vs. 0.93 for singleton births (53.3\% M). Previous studies of Holstein herds reported stillbirth rates from singleton births between 3.2 and $5.4 \%$, and for calves born as twins between 12.9 and 15.7\% (Eddy et al., 1991; Mee, 1991; Day et al., 1995). Our incidences of perinatal mortality within $24 \mathrm{~h}$ after birth agree with those of Cady and Van Vleck (1978), who reported an incidence of mortality of $5.9 \%$ for calves born as singletons and $22.4 \%$ for calves born as twins. They speculated decreased gestation length and greater incidence of dystocia for cows calving twins as the cause of decreased perinatal viability for calves born as twins. 
Table 4. Reported twin mortality for Holstein cows from 1996 to 2004 by sex of the calf and parity of the dam at calving

\begin{tabular}{|c|c|c|c|c|c|c|c|}
\hline \multirow[b]{3}{*}{ Status $^{1}$} & \multirow[b]{3}{*}{$\mathrm{Sex}^{2}$} & \multicolumn{6}{|c|}{ Parity of dam at calving } \\
\hline & & \multicolumn{2}{|c|}{ Nulliparous } & \multicolumn{2}{|c|}{ Primiparous } & \multicolumn{2}{|c|}{ Multiparous } \\
\hline & & $\%$ & $\mathrm{n}$ & $\%$ & $\mathrm{n}$ & $\%$ & $\mathrm{n}$ \\
\hline \multirow[t]{3}{*}{ AA } & MM & 18.07 & 1,755 & 20.88 & 6,498 & 21.18 & 11,698 \\
\hline & $\mathrm{FF}$ & 17.65 & 1,714 & 20.53 & 6,391 & 19.35 & 10,686 \\
\hline & $\mathrm{MF}$ & 25.85 & 2,511 & 31.98 & 9,953 & 32.17 & 17,767 \\
\hline \multirow[t]{3}{*}{ DD } & MM & 9.17 & 891 & 5.18 & 1,612 & 5.55 & 3,065 \\
\hline & $\mathrm{FF}$ & 4.93 & 479 & 2.52 & 784 & 2.74 & 1,514 \\
\hline & MF & 8.95 & 869 & 5.21 & 1,621 & 5.28 & 2,917 \\
\hline \multirow[t]{3}{*}{ DA } & MM & 3.67 & 356 & 3.53 & 1,100 & 3.52 & 1,945 \\
\hline & $\mathrm{FF}$ & 4.41 & 428 & 3.78 & 1,178 & 3.83 & 2,115 \\
\hline & MF & 7.31 & 710 & 6.38 & 1,986 & 6.38 & 3,526 \\
\hline
\end{tabular}

${ }^{1}$ Reported status of twin calves at birth in which both calves were reported born alive (AA), both calves were reported born dead (DD), or 1 calf was reported born dead and 1 calf was reported born alive (DA).

${ }^{2}$ Reported sex of twin calves in which both calves were reported to be male (MM), both calves were reported to be female (FF), or 1 calf was reported as male and 1 calf was reported as female (MF).

Table 5. Estimated odds ratios and 95\% confidence intervals (CI) for the effect of year (Yr), sex of calf, parity of dam, and season of calving on reported calf mortality for singleton births from Holstein cows from 1996 to 2004

\begin{tabular}{llclll}
\hline Covariate & Class & Estimate & $P$ & $\begin{array}{l}\text { Odds } \\
\text { ratio }\end{array}$ & $95 \%$ CI \\
\hline Parity of dam & Nulliparous & 0.434 & - & 1 & - \\
& Primiparous & -0.224 & $<0.001$ & 0.518 & $0.513-0.524$ \\
Sex & Multiparous & -0.210 & $<0.001$ & 0.526 & $0.521-0.530$ \\
& Male & 0.024 & $<0.001$ & 1.048 & $1.043-1.054$ \\
$\mathrm{Yr}$ & Female & -0.024 & - & 1 & - \\
$\mathrm{Yr} \times \mathrm{Yr}$ & & -0.046 & $<0.001$ & 0.956 & $0.942-0.969$ \\
$\mathrm{Yr} \times \mathrm{Yr} \times \mathrm{Yr}$ & & 0.021 & $<0.001$ & 1.022 & $1.018-1.025$ \\
$\mathrm{Yr} \times \mathrm{Parity}$ & & 0.002 & $<0.001$ & 1.002 & $1.001-1.002$ \\
& Nulliparous & 0.017 & - & 1.000 & - \\
$\mathrm{Season}$ of calving & Primiparous & -0.012 & $<0.001$ & 0.971 & $0.969-0.973$ \\
& Multiparous & -0.005 & $<0.001$ & 0.977 & $0.961-0.994$ \\
& Jan to Mar & 0.172 & $<0.001$ & 1.110 & $1.105-1.114$ \\
& Apr to Jun & -0.122 & $<0.001$ & 0.827 & $0.823-0.831$ \\
& Jul to Sep & -0.118 & $<0.001$ & 0.831 & $0.827-0.835$ \\
\hline
\end{tabular}

Table 6. Estimated calf mortality rate for singleton births from Holstein cows by year and parity, and change in estimated mortality rate relative to the previous year

\begin{tabular}{|c|c|c|c|c|c|c|}
\hline \multicolumn{4}{|c|}{$\begin{array}{l}\text { Estimated mortality rate } \\
\text { for singleton births, } \%\end{array}$} & \multirow{2}{*}{\multicolumn{3}{|c|}{$\begin{array}{l}\text { Change in mortality relative } \\
\text { to the previous year, } \%\end{array}$}} \\
\hline \multirow{2}{*}{$\begin{array}{l}\text { Year } \\
\text { of birth }\end{array}$} & \multirow[b]{2}{*}{ Nulliparous } & \multirow[b]{2}{*}{ Primiparous } & \multirow[b]{2}{*}{ Multiparous } & & & \\
\hline & & & & Nulliparous & Primiparous & Multiparous \\
\hline 1996 & 9.06 & 4.40 & 4.87 & - & - & - \\
\hline 1997 & 9.26 & 4.42 & 4.92 & 2.18 & 0.45 & 1.07 \\
\hline 1998 & 9.67 & 4.51 & 5.06 & 4.19 & 2.15 & 2.75 \\
\hline 1999 & 10.21 & 4.67 & 5.27 & 5.29 & 3.36 & 3.94 \\
\hline 2000 & 10.81 & 4.85 & 5.50 & 5.53 & 3.65 & 4.23 \\
\hline 2001 & 11.37 & 5.00 & 5.71 & 4.94 & 3.04 & 3.62 \\
\hline 2002 & 11.78 & 5.08 & 5.83 & 3.52 & 1.51 & 2.11 \\
\hline 2003 & 11.93 & 5.03 & 5.81 & 1.25 & -0.98 & -0.35 \\
\hline 2004 & 11.70 & 4.81 & 5.60 & -1.95 & -4.51 & -3.82 \\
\hline
\end{tabular}


Table 7. Estimated odds ratios and $95 \%$ confidence intervals (CI) for the effect of year (Yr), parity of dam, and season of calving on calf mortality after a twin birth from Holstein cows from 1996 to 2004

\begin{tabular}{llclll}
\hline Variable & Class & Estimate & $P$ & $\begin{array}{l}\text { Odds } \\
\text { ratio }\end{array}$ & $95 \%$ CI \\
\hline Parity of dam & Nulliparous & 0.410 & - & 1 & - \\
& Primiparous & -0.232 & $<0.001$ & 0.526 & $0.519-0.533$ \\
& Multiparous & -0.177 & $<0.001$ & 0.556 & $0.521-0.530$ \\
$\mathrm{Yr}$ & -0.048 & $<0.001$ & 0.953 & $0.942-0.969$ \\
$\mathrm{Yr} \times \mathrm{Yr}$ & 0.018 & $<0.001$ & 1.018 & $1.018-1.025$ \\
$\mathrm{Yr} \times \mathrm{Yr} \times \mathrm{Yr}$ & & 0.001 & $<0.001$ & 1.001 & $1.001-1.002$ \\
$\mathrm{Season}$ of calving & & 0.050 & $<0.001$ & 0.989 & $0.943-1.038$ \\
& Jan to Mar & -0.101 & $<0.001$ & 0.851 & $0.812-0.892$ \\
& Apr to Jun & -0.011 & $=0.42$ & 0.931 & $0.890-0.973$ \\
& Jul to Sep & 0.061 & - & 1 & - \\
\hline
\end{tabular}

Calf Sex. The overall reported singleton mortality did not differ based on sex of the calf, with 7.2 vs. $7.3 \%$ for $\mathrm{M}$ and $\mathrm{F}$ calves, respectively (Table 5). For samesex twin pairs, calf mortality was greater $(P<0.01)$ for $\mathrm{M}(25.1 \%)$ than for $\mathrm{F}(18.3 \%)$ twin pairs, whereas calf mortality for mixed-sex twins was $20.3 \%$ (Table 4). Contrary to these results, we expected greater calf mortality for singleton $\mathrm{M}$ compared with singleton $\mathrm{F}$ calves based on previous studies reporting greater stillbirth rates and risk of dystocia among $\mathrm{M}$ twins (Mee, 1991; Berger et al., 1992). An ambiguous definition of perinatal mortality by herd personnel, in some cases extending beyond $24 \mathrm{~h}$ after birth, could explain this discrepancy. Male calves are of little value to dairy producers and may leave a farm within hours or days after birth, thereby reducing the percentage of $\mathrm{M}$ calves that perished on the farm.

Season. Greater calf mortality occurred during the cold seasons [January to March (S1) and October to December (S4)] compared with warmer months [April to June (S2) and July to September (S3)] for both singletons $(8.0$ vs. $6.4 \% ; P<0.01 ; \mathrm{OR}=1.3)$ and twins $(22.5$ vs. $20.5 \% ; P<0.01$; OR $=1.12$; Table 5 and Figure 9 ). Interestingly, Johansson and Berger (2003) reported a
$15 \%$ increase in the risk of dystocia for calves born during the winter months after an analysis of 4,528 calving records collected in the Midwest United States over a 30 -yr period.

\section{Reported Calf Sex Ratio}

The percentage of singleton $\mathrm{M}$ births was $53.3 \%$ and varied among herds (Figure 10). Although the reported sex ratio for twins favored $\mathrm{M}$ calves (51.9\%), it was less divergent than that observed for $\mathrm{M}$ born as singletons. Likewise, in a review of the literature from 7 Northern European breeds of cattle, Johansson et al. (1974) reported that the proportion of $\mathrm{M}$ was less for calves born as twins compared with calves born as singletons (50.7 vs. $51.5 \%$ ). No differences in calf sex ratio were observed because of parity of the dam, contrary to that reported by Ryan and Boland (1991), in which sex ratio was similar for first-lactation cows but favored $\mathrm{M}$ for cows of $>1$ lactation. In the present study, same-sex twin pairs $(30.1 \% \mathrm{MM}$ and $26.3 \% \mathrm{FF})$ occurred more frequently than mixed-sex pairs $(43.6 \% \mathrm{MF})$. Although this finding could be interpreted as a greater occurrence of monozygotic twins, a previous study reported that

Table 8. Estimated calf mortality rate for twin births from Holstein cows by year and parity and change in estimated mortality rate relative to the previous year

\begin{tabular}{|c|c|c|c|c|c|c|}
\hline \multirow[b]{2}{*}{$\begin{array}{l}\text { Year } \\
\text { of birth }\end{array}$} & \multicolumn{3}{|c|}{$\begin{array}{l}\text { Estimated mortality rate } \\
\text { for twin births, \% }\end{array}$} & \multicolumn{3}{|c|}{$\begin{array}{l}\text { Change in mortality relative } \\
\text { to the previous year, } \%\end{array}$} \\
\hline & Nulliparous & Primiparous & Multiparous & Nulliparous & Primiparous & Multiparous \\
\hline 1996 & 30.72 & 18.91 & 19.77 & - & - & - \\
\hline 1997 & 30.64 & 18.86 & 19.71 & -0.26 & -0.30 & -0.30 \\
\hline 1998 & 30.98 & 19.10 & 19.97 & 1.11 & 1.29 & 1.28 \\
\hline 1999 & 31.57 & 19.53 & 20.41 & 1.88 & 2.20 & 2.18 \\
\hline 2000 & 32.24 & 20.02 & 20.92 & 2.08 & 2.45 & 2.42 \\
\hline 2001 & 32.82 & 20.44 & 21.35 & 1.74 & 2.05 & 2.03 \\
\hline 2002 & 33.10 & 20.66 & 21.57 & 0.86 & 1.02 & 1.01 \\
\hline 2003 & 32.91 & 20.52 & 21.43 & -0.57 & -0.67 & -0.66 \\
\hline 2004 & 32.08 & 19.91 & 20.80 & -2.60 & -3.08 & -3.04 \\
\hline
\end{tabular}




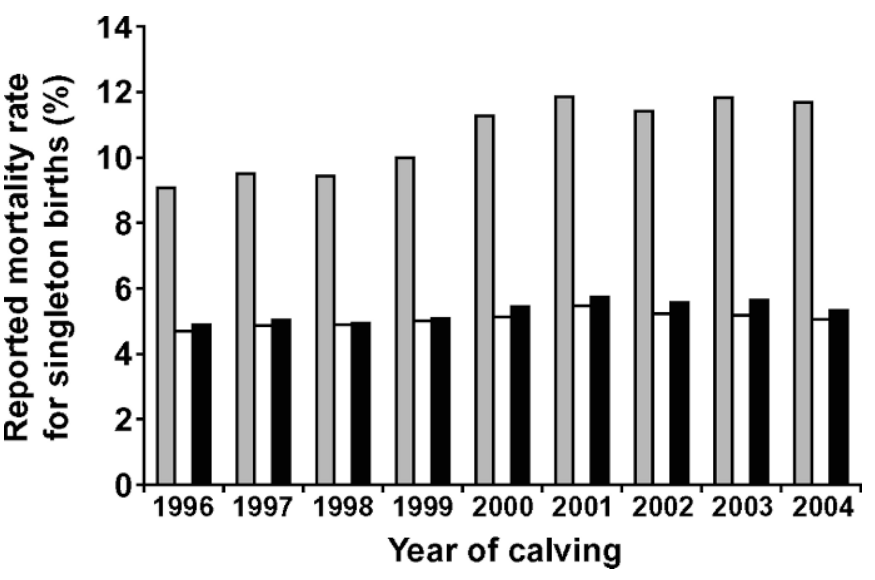

Figure 7. Singleton birth calf mortality for Holstein dairy cattle by parity of dam and year of calving. Gray bars = nulliparous heifers; open bars = primiparous cows; black bars = multiparous cows.

only $5 \%$ of all twins in cattle are monozygotic (Silva del Río et al., 2006). Perhaps the exposure of 2 oocytes to similar environmental conditions during the same estrus cycle could have increased their likelihood of being fertilized by sperm of the same sex. In support of this concept, several factors have been hypothesized to influence sex ratio, including vaginal and uterine $\mathrm{pH}$ (Guerrero, 1975), and maturity of the oocyte and time of timed AI (Pursley et al., 1998).

\section{Estimation of Heifers Available for Herd Replacements}

In the present study, the proportion of $\mathrm{F}$ available for herd replacements per calving event was $43.3 \%$ for

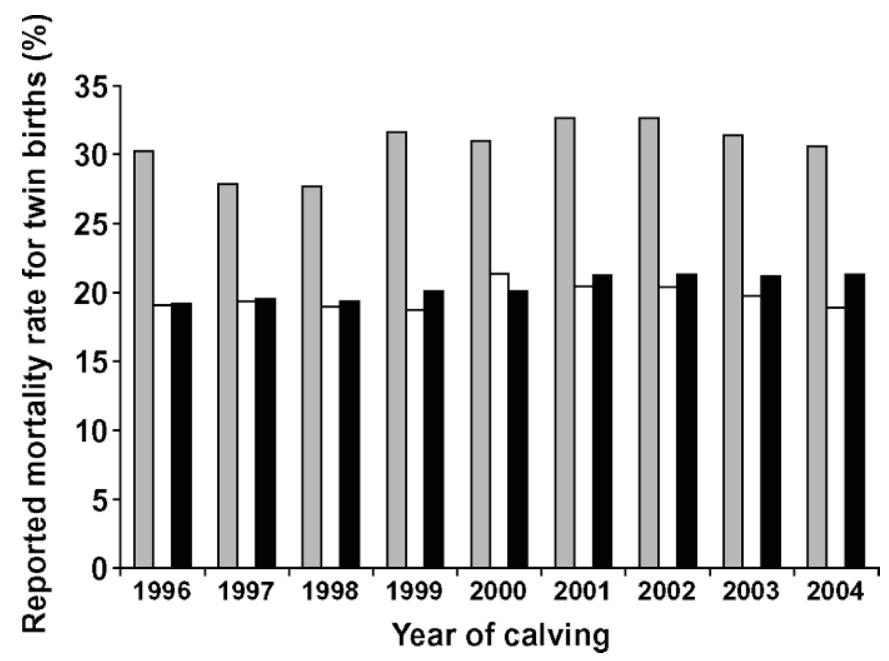

Figure 8. Twin calf mortality for Holstein dairy cattle by parity of dam and year of calving. Gray bars = nulliparous heifers; open bars = primiparous cows; black bars = multiparous cows.

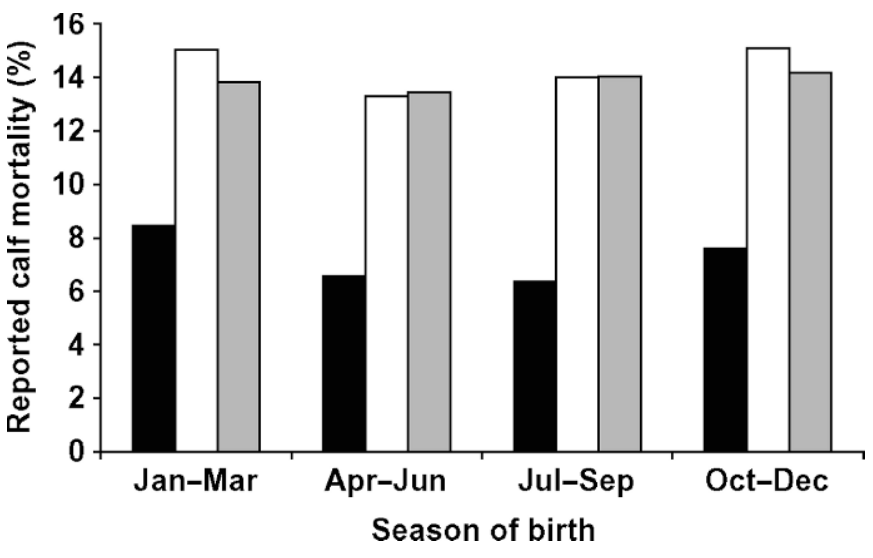

Figure 9. Calf mortality for Holstein dairy cattle from 1996 to 2004 by season of birth. Black bars = singleton births; open bars = twin births in which one calf was born alive and the other was dead; gray bars $=$ twin births in which both calves were dead. Mortality was greater $[P<0.01$; odds ratio $(\mathrm{OR})=1.2]$ for calves born from October to March than for calves born from April to September.

a singleton birth vs. $42.9 \%$ for twin births when only the F born alive in same-sex pairs were included. Similarly, Nielen et al. (1989) estimated the proportion of $\mathrm{F}$ available for herd replacements at $48.0 \%$ for singleton births and $42.0 \%$ for twin births. However, a more dramatic reduction in females available for replacements has been reported after twin births compared with singleton births when accounting for abortions ( 43.2 vs. $34 \%$; Erb and Morrison, 1985), and for abortions and pregnancy losses (42.2 vs. 29.2\%; Day et al., 1995).

\section{CONCLUSIONS}

Although specific factors cannot be implicated, the increase in twinning across time suggests a concurrent

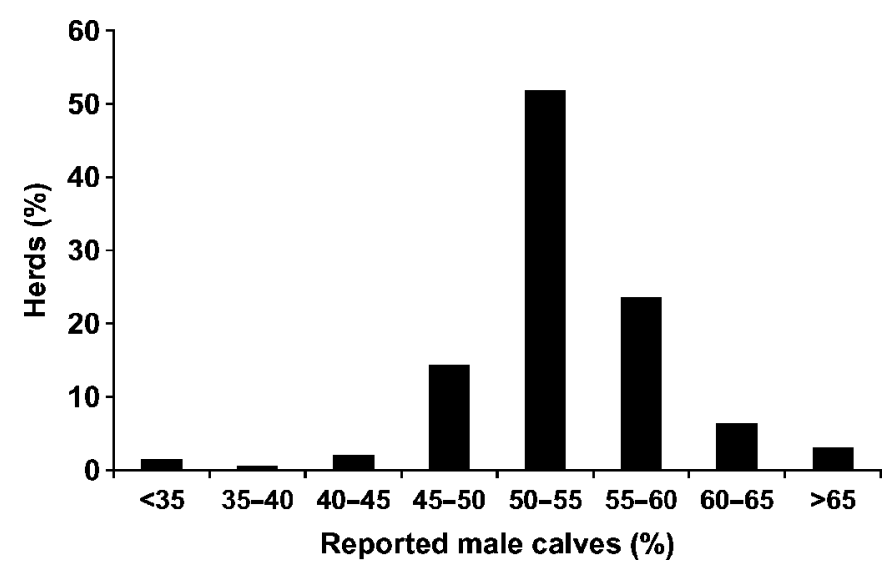

Figure 10. Distribution of male calves born from Holstein dairy cattle from 1996 to 2004 by herd. Only $18 \%$ of the herds in the data set reported more births of female than male calves during the study period. 
change in one or more causative factors associated with twinning during the 9-yr study period. Parity of the dam and season of conception were identified as risk factors for twinning. The reported calf mortality was high even on the smaller farms. Greater perinatal losses were observed for calves born as twins and for calves born from nulliparous dams. Finally, the secondary calf sex ratio favors male calves for both singleton and twin births.

\section{ACKNOWLEDGMENT}

We thank the Minnesota DHIA for use of their records to conduct this analysis.

\section{REFERENCES}

Bar-Anan, R., and J. C. Bowman. 1974. Twinning in Israeli-Friesian dairy herds. Anim. Prod. 18:109-115.

Beerepoot, G. M., A. A. Dykhuizen, M. Nielen, and Y. H. Schukken. 1992. The economics of naturally occurring twinning in dairy cattle. J. Dairy Sci. 75:1044-1051.

Berger, P. J., A. C. Cubas, K. J. Koehler, and M. H. Healey. 1992. Factors affecting dystocia and early calf mortality in Angus cows and heifers. J. Anim. Sci. 70:1775-1786.

Cady, R. A., and L. D. Van Vleck. 1978. Factors affecting twinning and effects of twinning in Holstein dairy cattle. J. Anim. Sci. 46:950-956.

Day, J. D., D. W. Leon, and C. E. Franti. 1995. Twin pregnancy diagnosis in Holstein cows: Discriminatory powers and accuracy of diagnosis by transrectal palpation and outcome of twin pregnancies. Can. Vet. J. 36:93-97.

Eddy, R. G., O. Davies, and C. David. 1991. An economic assessment of twin births in British dairy herds. Vet. Rec. 129:526-529.

Erb, R. E., and R. A. Morrison. 1958. Effects of twinning on reproductive efficiency in a Holstein-Friesian herd. J. Dairy Sci. 42:512-519.

Fricke, P. M. 2001. Review: Twinning in dairy cattle. Prof. Anim. Sci. 17:61-67.

Guerrero, R. 1975. Type and time of insemination within the menstrual cycle and the human sex ratio at birth. Stud. Fam. Plann. 6:367-371.

Hosmer, D., and S. Lemeshow. 2000. Applied Logistic Regression. 2nd ed. Wiley-Interscience, John Wiley \& Sons, New York, NY.

Johanson, J. M., and J. Berger. 2003. Birth weight as a predictor of calving ease and perinatal mortality in Holstein cattle. J. Dairy Sci. 86:3745-3755

Johanson, J. M., P. J. Berger, B. W. Kirkpatrick, and M. R. Dentine. 2001. Twinning rates for North American Holstein sires. J. Dairy Sci. 84:2081-2088.

Johansson, I., B. Lindhe, and F. Pirchner. 1974. Causes of variation in the frequency of monozygous and dizygous twinning in various breeds of cattle. Hereditas 78:201-234.
Karlsen, A., J. Ruane, G. Klemetsdal, and B. Heringstad. 2000. Twinning rate in Norwegian cattle: Frequency, (co)variance components, and genetic trends. J. Anim. Sci. 78:15-20.

Kinsel, M. L., W. E. Marsh, P. L. Ruegg, and W. G. Etherington. 1998. Risk factors for twinning in dairy cows. J. Dairy Sci. 81:989-993.

Larvor, P. 1975. General assessment of calf mortality in France. Pages 17-21 in Perinatal Ill-Health in Calves. J. M. Rutter, ed. Commision of the European Communities, Coordination of $\mathrm{Ag}$ ricultural Research, Brussels, Belgium.

Mee, J. F. 1991. Perinatal calf mortality-recent findings. Ir. Vet. J. 44:80-83.

Meyer, C. L., P. J. Berger, J. R. Thompson, and C. G. Sattler. 2001. Genetic evaluation of Holstein sires and maternal grandsires in the United States for perinatal survival. J. Dairy Sci. 84:12461254

Nielen, M., Y. H. Schukken, D. T. Scholl, H. J. Wilbrink, and A. Brand. 1989. Twinning in dairy cattle: A study of risk factors and effects. Theriogenology 32:845-862.

Philipsson, J. 1976. Studies on calving difficulty, stillbirth and associated factors in Swedish cattle breeds. I. General introduction and breed averages. Acta Agric. Scand. 26:151-164.

Pursley, J. R., R. W. Silcox, and M. C. Wiltbank. 1998. Effect of time of artificial insemination on pregnancy rates, calving rates, pregnancy loss, and gender ratio after synchronization of ovulation in lactating dairy cows. J. Dairy Sci. 81:2139-2144.

Rivera, H., H. Lopez, and P. M. Fricke. 2004. Fertility of Holstein dairy heifers after synchronization of ovulation and timed AI or AI after removed tail chalk. J. Dairy Sci. 87:2051-2061.

Rivera, H., H. Lopez, and P. M. Fricke. 2005. Use of intravaginal progesterone-releasing inserts in a synchronization protocol before timed AI and for synchronizing return to estrus in Holstein heifers. J. Dairy Sci. 88:957-968.

Ron, M., E. Ezra, and J. I. Weller. 1990. Genetic analysis of twinning rate in Israeli Holstein cattle. Genet. Sel. Evol. 22:349-360.

Ryan, D. P., and M. P. Boland. 1991. Frequency of twin births among Holstein-Friesian cows in a warm dry climate. Theriogenology 36:1-10.

Sartori, R., G. J. de Rosa, and M. C. Wiltbank. 2002. Ovarian structures and circulating steroids in heifers and lactating cows in summer and lactating and dry cows in winter. J. Dairy Sci. $85: 2813-2822$.

SAS Institute. 1999. User's Guide: Statistics. Version 9 Edition. SAS Inst., Inc., Cary, NC.

Sellers, K. C., G. F. Smith, and P. D. P. Wood. 1968. An investigation into calf mortality in the first eight weeks of life in England and Wales. Br. Vet. J. 124:89-94.

Silva del Río, N., B. W. Kirkpatrick, and P. M. Fricke. 2006. Observed frequency of monozygotic twinning in Holstein dairy cattle. Theriogenology 66:1292-1299.

Simensen, E. 1982. An epidemiological study of calf health and performance in Norwegian dairy herds. I. Mortality: Literature review, rates and characteristics. Acta Agric. Scand. 32:411-419.

Von Vandeplassche, M., R. Butaye, and R. Bouters. 1979. The twin capacity of the uterus in heifers and cows. Dtsch. Tieriirzgl.Wschr. 86:470-473.

Wijeratne, W. V. S., and D. L. Stewart. 1970. Stillbirths in cattle. Br. Vet. J. 126:238-253.

Wiltbank, M. C., P. M. Fricke, S. Sangsritavong, R. Sartori, and O. J. Ginther. 2000. Mechanisms that prevent and produce double ovulations in dairy cattle. J. Dairy Sci. 83:2998-3007. 